Revista de Economia Política, vol. 37, nº 1 (146), pp. 243-258, janeiro-março/2017

\title{
Cooperação monetária: Uma análise sobre o SUCRE
}

\author{
Monetary cooperation: an analysis on SUCRE
}

ALEXANDRE JERÔNIMO DE FREITAS

MARCELO PEREIRA FERNANDES*

RESUMO: A iniciativa do Sistema Único de Compensação Regional de Pagamentos, o SUCRE, acertado entre os principais países que compõe a ALBA, nasceu num contexto internacional de grande turbulência provocado pela crise financeira de 2008. Ainda em processo de consolidação, o sistema possui metas ambiciosas, entre elas a dissociação progressiva do uso do dólar. O objetivo deste artigo é analisar o SUCRE em vigor desde janeiro de 2010. A iniciativa poderá se tornar um passo fundamental para a construção de uma nova arquitetura financeira regional que reduza a vulnerabilidade externa e as assimetrias estruturais da região.

PALAVRAS-CHAVE: SUCRE; ALBA; comércio; moeda.

ABSTRACT: The initiative of the Unified System for Regional Compensation, the so-called SUCRE, concerted among the main countries that comprise ALBA, born in a context of great international turmoil caused by the financial crisis of 2008 . Still in the consolidation process, the system has very ambitious goals, including the use of the progressive decoupling of the dollar. The aim of this paper is to analyze the SUCRE in force since January 2010. The initiative may be a key step towards construction of a new regional financial architecture to reduce external vulnerability and structural asymmetries in the region.

KEYWORDS: SUCRE; ALBA; trade; currency.

JEL Classification: F02.

\section{INTRODUÇÃO}

O Sistema Único de Compensação Regional de Pagamentos (SUCRE) entrou em vigor em 27 de janeiro de 2010 entre as principais economias que integram a Alternativa Bolivariana para os Povos da Nossa América - Tratado de Comércio

\footnotetext{
* Professores do Instituto de Ciências Sociais Aplicadas (ICSA) da Universidade Federal Rural do Rio de Janeiro (UFRRJ). E-mail: alexandrefreitas76@gmail.com e mapefern@gmail.com. Submetido: 3/ setembro/2013; Aprovado: 26/novembro/2015.
} 
dos Povos (ALBA-TCP) ${ }^{1}$. Um mercado de aproximadamente 68 milhões de habitantes, ainda pouco desenvolvido.

A sua criação data da III Reunião Extraordinária dos chefes de Estado da ALBA em 26 de novembro de 2008. Na reunião as autoridades chegaram a um acordo para formação de uma zona monetária. O SUCRE foi assinado pelos chefes de Estado da ALBA em 16 de abril de 2009. Em linhas gerais o SUCRE é um "mecanismo dinamizador de la cooperación y la complementación productiva, orientado al desarrollo compartido de la región latinoamericana y caribeña [...]" (BCV, 2012).

A iniciativa nasceu num contexto internacional de grande turbulência provocado pela crise financeira internacional de 2008 . Na visão das autoridades dos países que formam a ALBA, a crise reafirmou a necessidade de se construir uma nova arquitetura financeira regional que reduza a vulnerabilidade externa e as assimetrias estruturais dos seus países, impulsionando a capacidade produtiva e o comércio na região. E essa nova arquitetura passa pela dissociação progressiva do uso do dólar na região (Consejo, 2011; Puñal, 2009, p. 80).

Assim, conforme expresso pelo informe das autoridades do SUCRE (Consejo, 2010), podemos citar pelo menos sete objetivos do sistema: i) dissociar a utilização progressiva do dólar no comércio intrarregional; ii) diminuir o uso de divisas para realização de pagamentos internacionais; iii) incorporar novos atores aos fluxos de comércio exterior; iv) incentivar o equilíbrio comercial entre os países participantes, como um mecanismo para reduzir as assimetrias, gerar novos mecanismos estabilizadores e fortalecer o próprio sistema.; v) promover a expansão do comércio entre os países participantes, com base em complementaridade produtiva; vi) proteger ante os impactos negativos das crises financeiras globais; vii) estabelecer as bases para o aprofundamento de novos mecanismos de integração regional nos âmbitos políticos e sociais.

O objetivo deste artigo é analisar o SUCRE, a recente experiência de cooperação monetária e financeira entre os países da ALBA. Ainda em processo de consolidação, está evidente que se trata de uma iniciativa bastante ambiciosa, como demonstram seus objetivos. Apesar disso o SUCRE vem superando as desconfianças iniciais que todo projeto desta magnitude carrega, ainda mais em se tratando de economias em desenvolvimento.

Além desta introdução o artigo está organizado em mais quatro seções. $\mathrm{Na}$ segunda seção analisaremos a formação de um sistema de pagamentos regionais, $\mathrm{o}$ seu modo de operação e as vantagens que podem trazer às economias que decidem participar do sistema. Na terceira e quarta seções discutiremos a estrutura e a dinâmica do SUCRE, respectivamente. Será possível observar que o sistema tem uma estrutura relativamente complexa, e que, a despeito de até o momento abar-

\footnotetext{
${ }^{1}$ A ALBA-TCP é atualmente integrada pela República Bolivariana da Venezuela, Bolívia, Equador, Cuba, Nicarágua, São Vicente e Granadinas, Antígua e Barbuda e Dominica. Mas apenas os cinco primeiros utilizam o SUCRE.
} 
car uma parte diminuta do comércio da ALBA, já conseguiu alguns resultados positivos. E, na última seção, as considerações finais trataram dos desafios para a consolidação do sistema.

\section{SISTEMAS DE PAGAMENTO REGIONAIS}

Os Sistemas de Pagamento Regionais (doravante, SPR) são tidos como um primeiro passo na direção de uma cooperação monetária mais profunda. São vistos comumente como arranjos monetários que facilitam o comércio regional, na medida em que reduzem os custos de transação através da liquidação de pagamentos em moedas locais. Também, deve-se enfocar seu impacto sobre o uso de reservas internacionais nestas operações possibilitando uma redução de seu montante e liberando seu uso para possíveis ajustes no balanço de pagamentos, protegendo a economia nacional de choques externos que possam exigir ajustes recessivos (Fritz et al., 2010, p. 23; UNCTAD, 2011).

O seu modo de operação, sob a ótica dos usuários, é simples: caso uma firma peruana deseje importar uma mercadoria e/ou contratar um serviço de uma firma colombiana, ela deve utilizar-se de meios de pagamento aceitos na Colômbia. Ela pode adquirir o montante diretamente em pesos colombianos ou, mais comum, em uma divisa, como o dólar para depois convertê-la na moeda colombiana. Os custos relacionados com a conversão das moedas encarecem a transação - podendo até inviabilizá-la, dependo do montante da operação.

Uma forma de evitá-los seria a criação de um SPR no qual, a partir de um acordo entre os bancos centrais dos dois países, a firma peruana pagasse pelo serviço em novo-sol e a firma colombiana recebesse em pesos colombianos. A transação ocorreria com uso apenas de moedas locais sem a necessidade de operar com uma terceira moeda. A conversão das moedas ficaria sob responsabilidade dos bancos centrais.

A redução no uso de moeda estrangeira no comércio intrarregional não é a única forma de reduzir os custos deste comércio. É possível reduzir o número final de transações efetuadas pelo SPR ao necessário para compensar os saldos líquidos entre os países.

Estipula-se um período de tempo durante o qual as operações, efetivadas diariamente, são contabilizadas através de uma Câmara de Compensação criada pelos bancos centrais.

Ao fim do período, as transações de mesmo montante são canceladas e o volume final de cada compensação refletiria somente a diferença entre vendas e compras acumuladas durante o período estipulado. Logo, créditos e débitos são cancelados sem a necessidade de uso de divisas, restando apenas o saldo final a ser liquidado. Caso cada transação seja liquidada individualmente, como num sistema descentralizado, todas as compras e vendas envolveriam o uso de alguma moeda internacional. Vejamos o quadro abaixo: 


\begin{tabular}{c|c|c|c}
\hline & Importação & Exportação & Saldo \\
\hline Pais A & 100 milhões & 120 milhões & 20 milhões \\
\hline País B & 120 milhões & 100 milhões & -20 milhões \\
\hline
\end{tabular}

$\mathrm{Na}$ ausência de um sistema de pagamentos entre os países, o país A precisaria utilizar 100 milhões numa terceira moeda aceita pelo país B que, por sua vez, precisaria de um montante de 120 milhões. Com um sistema de pagamentos nos moldes explicados acima, apenas o saldo líquido precisaria ser quitado, logo o país B precisaria apenas de 20 milhões e o país A não utilizaria nada.

Assim, para pagar pelo comércio intrarregional, o banco central do país em déficit precisa apenas transferir a moeda reserva no fim do período de compensação. Não é necessário operar com volume bruto de divisas diariamente, mas apenas com os montantes líquidos no final do período de compensação.

Para esta Câmara de Compensação funcionar é preciso que os bancos centrais criem linhas de crédito bilaterais cujo prazo seja, no mínimo, igual ao do período de compensação (Fritz et al., 2010, p. 6). Enquanto as operações vão sendo efetuadas pelos usuários e os montantes em moeda nacional vão sendo transferidos, as dívidas vão se acumulando nas contas dos bancos centrais. Ao final do período, quando a compensação é efetuada, apenas o saldo credor ou devedor é efetivamente liquidado.

Portanto, mais do que reduzir os custos de transação, este sistema provê liquidez durante o período de liquidação, permitindo que os países possam expandir as importações mesmo com restrições de reservas internacionais. Alivia a pressão sobre a economia interna da necessidade de gerar superávits comerciais através de ajustes recessivos.

A viabilidade destes sistemas de pagamento está diretamente relacionada a forma como este será acordado pelos países participantes. $\mathrm{O}$ uso do acordo pode ser obrigatório para todas as operações efetuadas no comércio intrarregional - um sistema fechado. Também é possível implementá-lo de forma facultativa, onde os usuários seriam livres para efetuar suas operações através do acordo - sistema aberto. Por fim, os países participantes poderiam tornar obrigatórias apenas algumas operações, transações específicas com certas mercadorias, ou, ainda, tornar o uso do acordo compulsório para empresas estatais - sistema misto.

No caso de sistemas abertos, a viabilidade do acordo estaria diretamente relacionada com as vantagens obtidas em termos de custos, que envolve as condições de crédito oferecidas pelo acordo junto com a moeda denominada para a compensação dos saldos líquidos finais. (UNCTAD, 2011, p. 32; Chang, 2000).

Como visto acima, o uso de uma câmara de compensação exige automaticamente a criação de linhas de crédito mútuas durante o período de compensação. De maneira a tornar o acordo mais atrativo, porém, os bancos centrais poderiam 
acordar outras formas de pagamento através da extensão das linhas de crédito, securitização do saldo devedor e swap de moedas.

A forma mais usual seria a extensão de créditos para além do período de compensação. Além das vantagens oferecidas ao país deficitário, que teria mais tempo para liquidar seu saldo devedor, a região ganharia mais fontes de liquidez em moeda local. Sua eficácia dependerá do diferencial de juros entre o crédito oferecido e o mercado internacional. Caso as condições de financiamento sejam favoráveis, é um estímulo a mais para a participação no SPR, além de um passo maior em direção à cooperação monetária regional.

Outra forma alternativa poderia ocorrer com o uso de títulos de dívida soberana emitidos em moeda nacional para pagar uma parcela do saldo devedor. Apenas com objetivo de facilitar o fluxo do comércio, os bancos centrais aceitariam tais títulos que seriam comercializados nos mercados financeiros dos países participantes. Seriam demandados por agentes interessados em operações no país emissor estimulando as relações econômicas regionais e poderiam vir a ser a pedra fundamental de um mercado regional de títulos soberanos (Ríos, 2010, p. 20-22).

Além disso, é possível que os países participantes utilizem-se do swap de moedas como forma de liquidar as dívidas pendentes. O importador se utilizará de uma linha de crédito fornecida pelo país do exportador que receberá o pagamento em sua própria moeda. Quando da redenção das obrigações, as posições entre os dois países são restabelecidas (Ríos, 2010, p. 22-23). Este mecanismo realça a necessidade de um comércio equilibrado para que o SPR tenha viabilidade de longo prazo, como será visto adiante.

A atratividade do uso do SPR também está vinculada à moeda denominada para compensação de déficits e superávits ao final do período de compensação. A possibilidade de saldar parte de sua dívida em moeda nacional é atrativa para o país deficitário. Por outro lado, o país superavitário poderá perder interesse caso não possa receber também em moeda conversível, já que nem sempre considerará interessante um crédito numa moeda cuja economia não lhe oferece muitas opções. Também é possível que se possa pagar parte do saldo devedor em moeda nacional e parte em moeda conversível. Uma última opção é a criação de uma unidade de conta específica para o uso no acordo - este ponto será tratado com mais detalhe na seção SUCRE.

A sustentabilidade de um SPR está diretamente ligada à questão econômica, mas também passa por motivos políticos. No plano econômico, o SPR será mais duradouro quanto mais eficiente for seu mecanismo monetário. Ao longo do tempo, é possível avaliar a importância do acordo a partir da diferença entre o volume e o número de transações totais - bruto - e o efetivamente liquidado (Chang, 2000 , p. 33). Trata-se de comparar o volume total de pagamentos do comércio regional com o volume canalizado pelo acordo.

Esta comparação possibilita diagnosticar a aceitação do sistema pelas firmas participantes no comércio regional, permitindo que se possam criar mecanismos que estimulem sua utilização.

Um tema mais delicado e essencial para que o acordo perdure são os desequi- 
líbrios persistentes que possam existir no comércio regional. Países cronicamente deficitários serão beneficiados com o uso do SPR, já que poderão postergar parte de seu saldo devedor e se utilizar de possíveis linhas de crédito adicionais, podendo ainda saldar seu déficit em moeda nacional. Por outro lado, os países superavitários poderão perder interesse no acordo na medida em que o montante de saldo acumulado restrinja suas possibilidades de investimento (Fritz et al., 2010, p. 7).

Se o destino do SPR está umbilicalmente ligado às características do comércio intrarregional., por outro lado também é possível utilizá-lo para tentar moldar em certa medida este comércio. Podem-se adotar alguns mecanismos que busquem suavizar os desequilíbrios, a partir da adoção do chamado "princípio da reciprocidade". Isto é, a adoção pelos países participantes de um compromisso de manter o equilíbrio no comércio intrarregional. Os países superavitários concederiam automaticamente, ao sistema de pagamentos, créditos que seriam transferidos aos países deficitários, incentivando aos superavitários acelerar - como forma de recuperação de seus créditos - seus mercados aos produtos dos deficitários, equilibrando assim o comércio regional (Aragão, 1984, p. 16).

Uma alternativa para a manutenção de um comércio equilibrado que viabilize o SPR é a discriminação de transações com certas mercadorias, caso do petróleo. Esta questão será analisada no contexto do SUCRE, mais à frente.

No entanto, estas propostas de criação de mecanismos de ajuste comercial englobam um nível de discriminação em favor dos mercados regionais que pode não condizer com a realidade do comércio intrarregional. Podem servir para incentivá-lo, contudo dificilmente será suficiente para transformar estruturalmente a pauta de exportação destes países.

Esta é uma questão estrutural de longo prazo que apenas o acordo monetário não será suficiente para resolver, é preciso que os países conjuguem uma vontade política comum em prol de uma integração regional. Desta forma:

"Los requisitos [...] para que los mecanismos propuestos produzcan el equilibrio del comercio intraregional de los países latinoamericanos sin que se reduzcan los niveles globales de ese intercambio [...] las hacen dependientes de decisiones politicas de gran alcance y que, de existir, significarían una adhesión efectiva de los países a la integración de sus mercados a nivel multinacional” (Aragão, 1984, p. 16).

Essa vontade política é que fará que o SPR se torne viável no longo prazo e possa servir como passo inicial de uma cooperação monetária e financeira mais profunda.

\section{A ESTRUTURA DO SUCRE}

O SUCRE é atualmente integrado pela seguinte estrutura: o Consejo Monetário Regional (CMR), uma Cámara Central de Compensación de Pagos (CCC), o 
Fondo de Reservas y Convergencia Comercial (FRCC), a unidade de conta comum, o "sucre" (XSU), além dos bancos centrais da Venezuela, Equador, Cuba, Nicarágua e Bolívia.

O CMR tem personalidade jurídica própria, sendo o órgão máximo de decisão do SUCRE incumbido de gerir o sistema ${ }^{2}$. O CMR pretende oferecer um espaço apropriado para discussão e coordenação das políticas cambiais, monetárias e comerciais dos países-membros a fim de garantir um funcionamento adequado do sistema (BCE, 2012, p. 5).

Por "funcionamento adequado" está suposta a noção de que o SUCRE deve adotar políticas que reduzam as assimetrias econômicas entre os países-membros. Com isso, o Conselho propõe políticas orientadas a expandir o comércio dentro do sistema, visando ao equilíbrio entre as partes.

No momento em que o SUCRE começou a funcionar foi definida certa quantidade de cotas e que cada país teria direito. É também o Conselho que defini a quantidade de cotas de sucres que cada país terá direito.

As transações são efetivadas através da CCC que, durante o período de compensação de seis meses, contabiliza todas as operações realizadas entre os países participantes. Só serão autorizadas transações que estejam diretamente ligadas ao comércio de bens e serviços, excluindo qualquer operação de caráter puramente financeiro (BCV, 2009, p. 9).

Os usuários do sistema poderão efetivar suas operações em moeda local utilizando-se não somente de pagamentos à vista, como também utilizando ordens de pagamento e instrumentos de crédito que são oferecidos pelos bancos operativos autorizados (BOA) do sistema.

O saldo destas operações será liquidado através das contas mantidas pelos bancos centrais dos países participantes no operador do sistema de compensação - Banco del Alba. Nos SPR usualmente apenas se contabilizam as operações para que, posteriormente, o saldo final seja liquidado. No caso do SUCRE, foi feita uma distribuição de crédito em sucres para cada país participante, segundo a fração do comércio de cada país-membro. Para isso foi usada a seguinte fórmula (Trujillo, 2012):

$z_{i}^{0}=\theta \cdot M_{i}$

$Z i=$ emissão inicial de sucres no país $i$;

$\theta=$ Proporção das importações projetadas do país $i$, originadas nos estados-membros do SUCRE a serem canalizados através deste sistema em seu primeiro período (semestre) de operações. Inicialmente se estabeleceu um valor inciail de $\theta$ $=0,20$;

\footnotetext{
${ }^{2}$ O CMR é constituído por um Diretório Executivo responsável pela direção e decisão do Conselho, uma Secretaria Executiva responsável pela administração, além de Comitês integrados por representantes de cada país com responsabilidade sobre questões de planejamento, comércio e finanças (Consejo, 2010).
} 
$M i=$ Importações projetadas do país $i$, originadas nos estados-membros do SUCRE.

Atualmente o sistema oferece aos países deficitários formas alternativas de liquidarem seu saldo negativo. É possível utilizar-se de crédito bilaterais entre os bancos centrais participantes ou podem efetuar operações comerciais de venda futura - através de pagamento antecipado de exportações - ou ainda utilizar-se do sobregiro intradiário através do FRCC (Consejo, 2013, p. 14).

Operado a partir do Banco de Desarrollo Económico y Social de Venezuela (BANDES), o FRCC apresenta dois objetivos. Primeiramente, o Fundo contribui para o funcionamento da CCC, fazendo a intermediação de recursos em sucres dos países com superávit até os países com déficit comercial dentro do Sistema, permitindo aos países deficitário financiamento durante (intradiário) e após (interperíodo) o período de compensação ${ }^{3}$ (Consejo, 2013, p. 19).

Em segundo lugar, o Fundo também provê financiamento de projetos dirigidos ao desenvolvimento de atividades econômicas que impulsionem as exportações em benefício dos países com déficits crônicos no comércio com os demais países-membros, além de financiar políticas anticíclicas em momentos de crises (Consejo, 2011, p. 11).

Os projetos de investimento devem ser efetuados em território dos países signatários cujo capital também deve ter origem nos mesmos. A possibilidade de que firmas tenham origem em mais de um país participante estimula a integração produtiva regional.

Portanto, o FRCC pode ser um instrumento relevante para reduzir as assimetrias comerciais, evitando ajustes recessivos por parte dos países deficitários, o que o torna uma importante inovação do sistema.

Inicialmente houve uma emissão de 152 milhões de sucres. De acordo com o Banco Central do Equador, numa situação em que o país precise de mais sucres do que disponibiliza no momento, devido ao aumento das importações, o banco central pode usar um mecanismo chamado de "sobregiro de sucre", que é regulado e limitado pelo CMR ou através da compra de sucres entre bancos centrais (BCE, 2012).

\footnotetext{
${ }^{3} \mathrm{O}$ aporte inicial do Fundo representou aproximadamente $5 \%$ da emissão correspondente a cada Estado membro, equivalente a US\$ 9,5 milhões (Consejo, 2013).
} 
Tabela 1: Emissões de Sucres (em milhões)

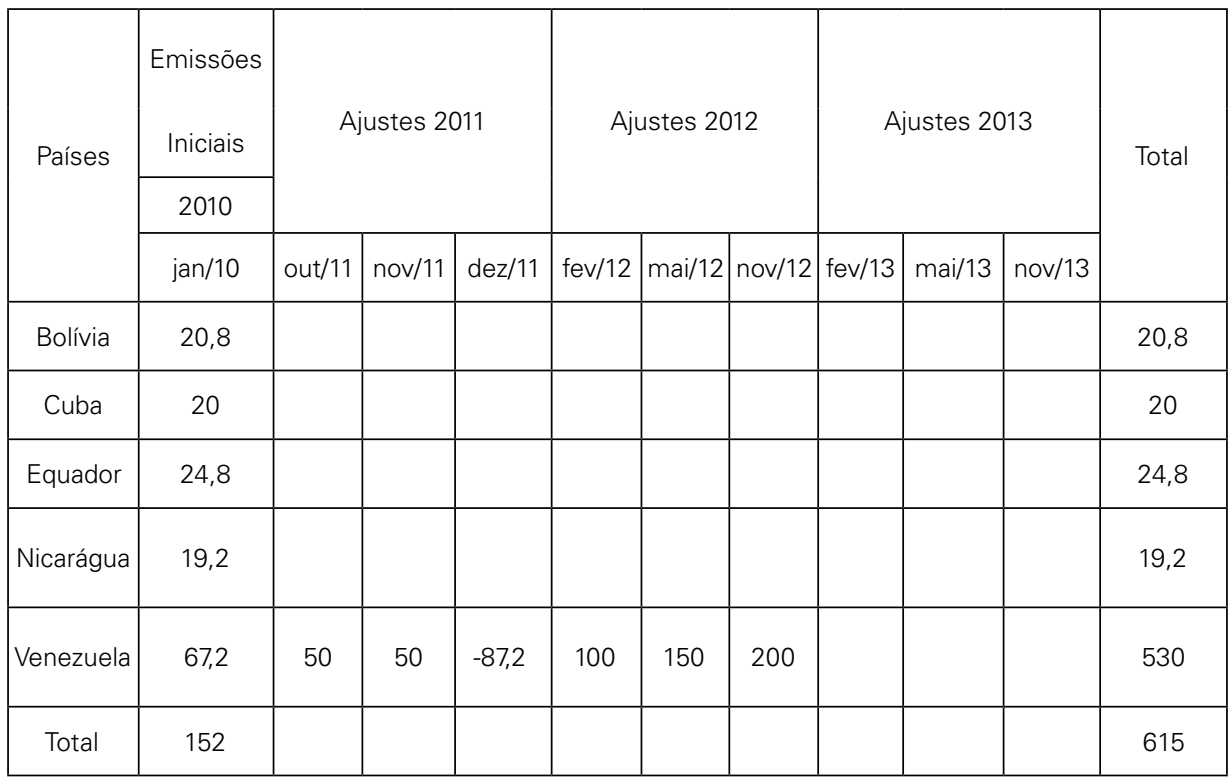

Fonte: Conselho Monetário do SUCRE

A criação de uma moeda virtual é a principal característica que distingue o SUCRE de outras iniciativas regionais de sistema de pagamentos na América Lati$\mathrm{na}^{4}$ (BCE, 2012).

A princípio o sucre não circulará como moeda de curso forçado, sendo utilizada exclusivamente como unidade de conta e meio de pagamento pelos bancos centrais dos países-membros ${ }^{5}$. Pelo menos uma vez ao ano o valor do sucre é calculado de acordo com a seguinte equação (Trujillo, 2012):

$$
\begin{aligned}
& N_{i}=\bar{W}_{i} T c_{i} \\
& \bar{W}_{i}=0.3 \frac{\text { media } P I B_{i}}{\sum_{i=1}^{n} \text { media } P I B_{i}}+0.3 \frac{\text { media } C E_{i}}{\sum_{i=1}^{n} \text { media } C E_{i}}+0.4 \frac{\text { media } C l_{i}}{\sum_{i=1}^{n} \text { media } C l}{ }_{i}
\end{aligned}
$$

$N$ = número de unidades de cada moeda local contidas em um sucre;

$W=$ Peso percentual de cada moeda na cesta de moedas de curso legal dos respectivos países

\footnotetext{
${ }^{4}$ O Sistema de Pagamentos em Moeda Local (SML) entre Brasil e Argentina, por exemplo, não utiliza uma moeda virtual.

${ }^{5}$ Até o momento não há nenhum plano formal para que o sucre se transforme em moeda de curso forçado.
} 
Tc = taxa de câmbio da moeda local com o "sucre" ou tipo de câmbio central.

$\mathrm{PIBi}=$ produto interno bruto per capita anual de renda do país $i$ nos 5 anos, a preços constantes do ano-base em USD;

$\mathrm{CE}=$ comércio extraregional do país $i$ (em USD);

$\mathrm{CI}=$ comércio intraregional do país $i$ (em USD);

Dessa forma, o valor do sucre é determinado usando duas cestas de moedas: i) uma cesta de moedas intrarregional., na qual abrange as taxas de câmbio das moedas nacionais dos países-membros do SUCRE, sendo que cada moeda na formação da cesta corresponde ao peso relativo das economias ${ }^{6}$ e, ii) uma cesta de moedas extrarregional que abrange as taxas de câmbio das principais moedas conversíveis internacionalmente ${ }^{7}$.

O uso de cestas de moedas permite que, a despeito da volatilidade das taxas de câmbio dos países-membros perante o dólar, o valor do sucre permaneça estável. Na medida em que ocorra uma desvalorização em uma moeda, sua parcela na cesta de moedas intrarregional será diminuída, evitando que a volatilidade desta moeda ressoe no valor em dólares do sucre.

O mecanismo tem funcionado a contento na medida em que o valor do sucre em dólares tem permanecido relativamente estável desde que foi lançado (ver gráfico abaixo). Contribuem muito para isso os regimes cambiais dos países-membros. O Equador possui uma economia dolarizada, fazendo com que o dólar também faça parte da cesta de moedas intrarregional. Cuba e Bolívia possuem um câmbio fixo em relação ao dólar. A Nicarágua, cuja moeda passa a entrar no cálculo a partir de 2013, possui um regime de câmbio fixo, mas ajustável (crawling peg) com o dólar.

A única moeda que flutua perante o dólar é o bolívar da Venezuela, que devido ao tamanho de sua economia, e ao peso de seu comércio intrarregional., exerce grande influência no sucre. Todavia, a despeito da volatilidade da moeda venezuelana perante o dólar em 2013 e 2014, o valor do sucre tem conseguido manter-se estável em seus limites de flutuação $\left(5 \%\right.$ para mais e para menos) ${ }^{8}$.

\footnotetext{
${ }^{6}$ Atualmente, com a entrada da Nicarágua, as moedas dos países-membros têm o seguinte peso: 1 boliviano $($ Bolívia $)=6,16 \% ; 1$ CUC $(\mathrm{Cuba})=13,65 \% ; 1$ dólar $($ Equador $)=25,57 \% ; 1$ bolívar $($ Venezuela $)=46,37 \%, 1$ córdoba (Nicaraguá) = 8,25. Cf. http://www.sucrealba.org/

${ }^{7}$ Inclui o Dólar, Euro, Yen, Libra e o Franco Suíço.

${ }^{8}$ Entre dezembro de 2008 e janeiro de 2014 o Fed, Banco Central dos Estados Unidos, levou a cabo a política de quantitative easing, o que torna a baixa volatilidade do sucre um tanto notável.
} 
Evolução da Taxa de Câmbio Dólar x Sucre

CÂMBIO INICIAL: 1 XSU = 1,2500 USD

CÂMBIO EM 31/12/2013: 1XSU=1,2480 USD

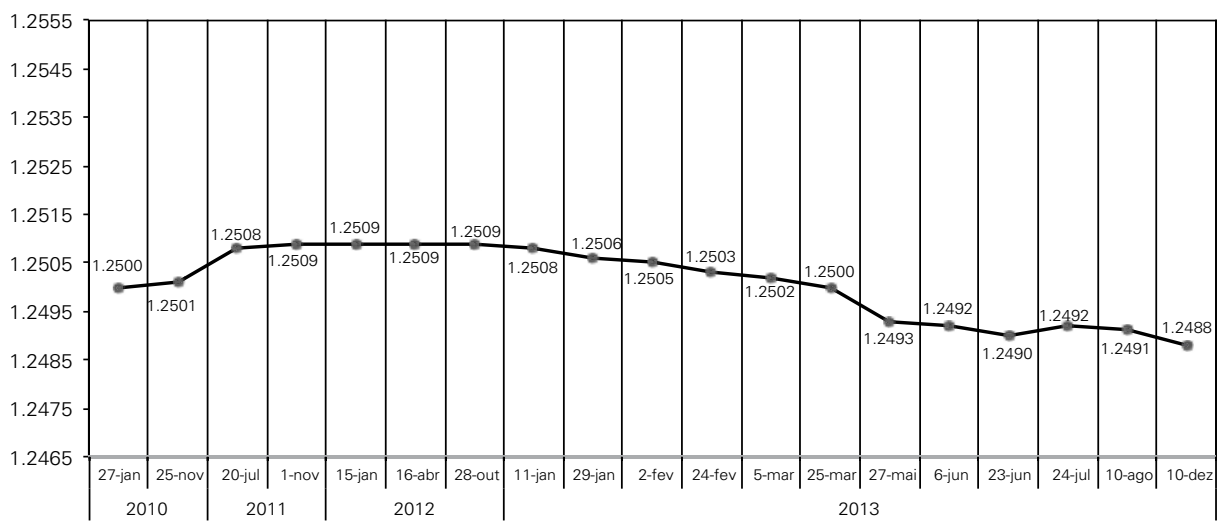

Tabela 2: Taxa de Câmbio: moedas nacionais/dólar

\begin{tabular}{|c|c|c|c|c|}
\hline País & 2010 & 2011 & 2012 & 2013 \\
\hline Bolívia & 7,02 & 6,94 & 6,91 & 6,91 \\
\hline Cuba & 1 & 1 & 1 & 1 \\
\hline Equador & 1 & 1 & 1 & 1 \\
\hline Venezuela & 4,24 & 4,29 & 4,29 & 6,05 \\
\hline
\end{tabular}

Fonte: Conselho Monetário do SUCRE

\section{A DINÂMICA DO SISTEMA}

Na prática o SUCRE vem avançando, mas como várias características do sistema ainda estão sendo executadas, o volume de negócios é reduzido.

Tabela 3: Total de Operações em Sucre

\begin{tabular}{|l|r|r|r|r|r|}
\hline & \multicolumn{1}{|c|}{2010} & \multicolumn{1}{c|}{2011} & \multicolumn{1}{c|}{2012} & \multicolumn{1}{c|}{2013} & \multicolumn{1}{c|}{$2014^{*}$} \\
\hline Operações & 6 & 431 & 2646 & 2094 & 742 \\
\hline Em Milhões (xsu) & 10,11 & 216,13 & 812,07 & 727,19 & 336,12 \\
\hline
\end{tabular}

* Os dados de 2014 vão até outubro

Fonte: Conselho Monetário do SUCRE

Comparando o comércio total entre os países-membros observa-se que o volume de comércio canalizado pelo SUCRE ainda é uma parcela reduzida (Tabelas 4 e 5). Em 2010 houve apenas seis operações realizadas através do SUCRE num valor total de XSU 10,1 milhões (USD 12,63 milhões). Em 2011 ocorreu um crescimento substancial: foram 431 operações num valor de XSU 216,13 milhões (USD 270,33 milhões) (Consejo, 2012, p. 21). O volume de sucres transacionados em 2012 foi de XSU 852,07 milhões (US\$ 1,1 bilhão), com 2.646 operações. Em 
2013 houve uma pequena redução: XSU 727,19 milhões (US\$ 908,95 milhões) para 2.094 operações?.

As operações de importações e exportações através do SUCRE em 2010 e 2012 ficaram divididas da seguinte forma ${ }^{10}$ :

Tabela 4

\begin{tabular}{lrrr}
\hline \multicolumn{1}{c}{ País importador } & Ano 2010 (em xsu) & Ano 2011 (em xsu) & Ano 2012 (em xsu) \\
\hline Bolívia & 89.823 & 840.820 & $1.022 .479,92$ \\
Cuba & 108.000 & 12.181 & 0 \\
Equador & 3.774 .124 & 34.505 .528 & $60.496 .728,87$ \\
Venezuela & 6.135 .695 & 180.773 .151 & $790.547 .395,04$ \\
Total & $10.107 .642,51$ & $216.131 .679,79$ & $852.066 .603,84$ \\
\hline
\end{tabular}

Fonte: Conselho Monetário do SUCRE

Tabela 5

\begin{tabular}{lr|r|r}
\hline \multicolumn{1}{c|}{ País exportador } & Ano 2010 (em xsu) & Ano 2011 (em xsu) & Ano 2012 (em xsu)* \\
\hline Bolívia & 4.241 .680 & 5.550 .262 & \\
Cuba & 0 & 2.082 .408 & $2.733 .731,94$ \\
Equador & 1.983 .839 & 175.947 .698 & \\
Venezuela & 3.882 .124 & 32.551 .313 & \\
Total & $10.107 .642,51$ & $216.131 .679,79$ & $852.066 .603,84$ \\
\hline
\end{tabular}

Fonte: Conselho Monetário do SUCRE

* Para 2012, apenas o valor das exportações de Cuba estão disponíveis.

Os dados disponíveis demonstram que o comércio está muito concentrado em apenas dois países. Durante o ano de 2013, do total de operações do acordo, 95,79\% envolveram Venezuela e Equador; 3,28\%, Bolívia e

Venezuela; 0,62\%, Cuba e Equador; 0,22\%, Nicarágua e Venezuela; Cuba e Venezuela, 0,08\% (Consejo, 2014, p. 41).

Analisando as operações por setor econômico, é possível verificar a participação crescente dos bens de consumo, o que pode refletir a maior participação de pequenas e médias empresas utilizando o acordo. A participação do setor industrial também é expressiva (até 2013), configurando uma pauta mais diversificada do que a estrutura de comércio tradicional entre os países, ratificando o desejo de

\footnotetext{
${ }^{9}$ Em 2013, até o momento, somente o valor total está disponível.

${ }^{10}$ No plano anual de exportações há uma série de mercadorias que não precisam de autorização para exportação. As mercadorias que estão fora do Plano necessitam de autorização quando a produção precisa de insumos importados; quando esses insumos não são utilizados não é necessário autorização (Consejo, 2011). O petróleo está fora do acordo.
} 
que este intercâmbio comercial promova também uma maior integração produtiva na região ${ }^{11}$ (Consejo, 2012, p. 24).

Tabela 6: Operações em Sucre por Setor Econômico

\begin{tabular}{|l|c|c|c|c|c|}
\hline & 2010 & 2011 & 2012 & 2013 & 2014 \\
\hline Agricultura & $79,30 \%$ & $19,70 \%$ & $12,88 \%$ & $2,87 \%$ & $9,12 \%$ \\
\hline Indústria & & $27,11 \%$ & $41,10 \%$ & $33,62 \%$ & $6,38 \%$ \\
\hline Comércio (Bens de Consumo) & $20,70 \%$ & $53,19 \%$ & $46,11 \%$ & $63,51 \%$ & $84,50 \%$ \\
\hline
\end{tabular}

Fonte: Conselho Monetário do SUCRE

Assim, apesar de muito incipiente e representar uma pequena parte do comércio total entre os países, a pauta comercial canalizada pelo SUCRE possui características distintas da pauta tradicional., podendo servir como importante elemento estimulador de uma integração econômica produtiva entre os países signatários.

Também é possível ter uma noção sobre a evolução inicial do sistema através de sua eficiência na redução nos custos de transação. Analisar quantitativamente a magnitude da redução dos custos de transação nestes primeiros anos de vigência do SUCRE envolveria analisar aspectos institucionais de cada país, o acesso em termos de custo de crédito e os ganhos de arbitragem das instituições financeiras nacionais com relação aos mercados de câmbio internacionais, o que evidentemente ainda não é possível avaliar.

Mesmo assim é possível ter uma ideia desta redução de custos através da diminuição do uso de dólares que o sistema proporciona aos bancos centrais de cada país envolvido, bastando para isso observar as Tabelas 1 e 2 acima. Em 2010, a Bolívia importou o equivalente a US\$112.278,00, porém como obteve um superávit em sucres, não precisou utilizar a moeda americana neste comércio. No mesmo ano, Cuba efetuou apenas uma importação equivalente a US\$ 135.000,00, sem exportações, de forma que não obteve ganhos, já que precisou liquidar seu saldo negativo ao final do período.

Ainda em 2010, o Equador importou o equivalente a US\$ 4.717.655,00, mas precisou apenas de US\$2.237.856,00 para liquidar seu saldo líquido final em sucre no período. Por fim, a Venezuela importou US\$ 7.669.618,00 em 2010, e liquidou seu saldo final com US\$2.816.963,00.

Em 2011, a Bolívia aumentou suas importações para o equivalente a US\$1.051.025,00; todavia, como manteve um saldo líquido positivo, novamente

\footnotetext{
${ }^{11}$ Segundo a CEPAL, os principais itens exportados são: Bolívia (2013): gás (52,4\%), prata (7,4\%); Cuba (2009): medicamentos (24,4\%), açúcar (14,1); Equador (2013): petróleo (54,8\%), bananas (9,5\%); Venezuela (2011) - petróleo e derivados (66,7\%). Em 2013, mas de 76\% do comércio em sucre foi de: atum, construções pré-fabricadas, veículos, aparatos mecânicos, produtos químicos, aparatos, eletrodomésticos (linha branca), produtos farmacêuticos e têxteis (Consejo, 2014, p. 43).
} 
não precisou utilizar dólares neste comércio regional. Já Cuba importou um montante de US\$ $15.226,00$, mas também manteve um saldo líquido positivo, não precisando da moeda americana.

O Equador conseguiu uma posição superavitária em 2011, de maneira que não precisou dispor dos US\$ 43.131.910 que seriam necessários para pagar suas importações. Já a Venezuela obteve um saldo negativo de US\$ 185.277.297,00, cujo montante é inferior às suas importações totais em 2011, que alcançaram US\$ 225.966.438,00.

Estes números ${ }^{12}$ mostram como o SUCRE pode se tornar um instrumento valioso para as economias dos países signatários devido à redução do uso de moedas conversíveis no comércio intrarregional. Mesmo os países com saldo negativo acabam utilizando menos do que seria necessário sem o acordo e, devido à liquidação final permitir que se faça apenas um pagamento por período, evita a necessidade de movimentação diária destes dólares.

\section{CONSIDERAÇÕES FINAIS}

A magnitude das transações efetuadas via SUCRE ainda é uma parcela pequena do comércio entre os países. Entretanto, deve-se levar em conta o fato de que o sistema se encontra ainda na etapa de implantação. Os mecanismos creditícios aprovados ainda estão em fase embrionária e não geraram a liquidez esperada. Além disso, a possibilidade de uso de moedas locais para a liquidação de parte do saldo líquido devedor também não foi efetuada.

Não obstante o SPR seja frequentemente visto como apenas um sistema de pagamento voltado para reduzir custos de transação, o SUCRE é uma ação mais ambiciosa que faz parte de um plano que visa a maior integração produtiva das economias participantes. A adoção de uma unidade de conta que exige certa coordenação cambial permite que seja um passo inicial para a criação de uma nova arquitetura financeira regional., essencial para que os projetos de desenvolvimento e as estratégias de integração política e econômica da região possam evoluir.

Mais do que o volume de comércio é importante analisar as suas características motivadas pela discriminação de mercadorias ("comércio administrado") efetivada pelo Acordo visando a um comércio equilibrado. Os dados apresentados na quarta seção demonstram como a preocupação de estimular um comércio equilibrado é fundamental para a viabilidade do sistema. Embora tenha que se levar em conta as assimetrias das economias envolvidas, é preciso que Bolívia, Cuba e Nicarágua tornem-se parceiros comerciais mais ativos para que não ocorram desequilíbrios crônicos no futuro.

Por sua vez, vale frisar que, devido à situação econômica e geopolítica de cada país, a economia no uso da moeda americana tem impactos diferentes em cada

${ }^{12}$ Os últimos divulgados por país. 
país. Devido ao bloqueio americano a Cuba, o país possui muitas dificuldades em manter um nível comércio estável com a economia internacional., reduzindo seu acesso a moedas conversíveis. Logo, do ponto de vista cubano trata-se de uma grande oportunidade para relaxar um pouco a forte restrição externa sofrida pelo país.

Outro país que possui interesse especial no acordo é o Equador. Embora não tenha tantas dificuldades como Cuba para obter moedas conversíveis, por se tratar de uma economia exportadora de petróleo como a Venezuela, trata-se de uma economia dolarizada, e por isso necessita muito da moeda americana para uso interno. Isto faz com que o país veja com bons olhos a redução de seu uso no comércio regional.

Por outro lado, como o SUCRE é um sistema de pagamentos aberto, ou seja, de uso facultativo por seus usuários, a participação do setor privado é muito importante para a viabilidade do acordo. Até 2013 as operações, exclusivamente privadas, aproximadamente $96 \%$ do total das operações com mais de 500 firmas de todos os países, utilizaram o comércio em sucres (Consejo, 2014, p. 43).

Se a participação privada é essencial para que o sistema ganhe credibilidade perante os usuários, é possível também estimular seu uso pelas instituições publicas e empresas estatais como forma de alavancar os montantes transacionados, estimulando não apenas o uso do sistema como também permitindo a expansão do crédito em sucres aos países signatários.

Por fim, é conveniente lembrar que a iniciativa de implantação do SUCRE é feita num momento muito particular em que a América Latina busca caminhos próprios para seu desenvolvimento econômico. Esses caminhos passam pelo crescimento da integração econômica da região, no qual uma maior cooperação monetária e financeira é um instrumento essencial para isso.

\section{REFERÊNCIAS BIBLIOGRÁFICAS}

ARAGÃO, José Maria (1984). “Los sistemas de pagos Latinoamericanos”. Integración Latinoamericana, n.94: 3-28.

BANCO CENTRAL DE VENEZUELA (BCV) (2012). Instructivo para la Tramitación de Operaciones Através del Sistema Unitario de Compensación Regional de Pagos (SUCRE). Disponível em: $<\mathrm{ht}-$ tp: www.bcv.org.ve/sucre/instruopesucre.pdf $>$. Acesso em: 01/2013.

BANCO CENTRAL DEL ECUADOR (BCE) (2012): Resumen de los elementos técnicos de La configuración del Sistema Unitario de Compensación Regional SUCRE. Disponível em: < http://www. bce.fin.ec/documentos/ServiciosBCentral/SUCRE/sucDoc08.pdf>. Acesso em: 01/2013

CONSEJO Monetario Regional del Sistema Unitario de Compensación Regional de Pagos (SUCRE) (2014). Los sistemas de pagos regionales en moneda local: la experiencia del sistema unitario de compensación regional de pagos (sucre).

CONSEJO Monetario Regional del Sistema Unitario de Compensación Regional de Pagos (SUCRE) (2014) “Informe de Gestión, 2013”. Disponível em: <http://www.sucrealba.org/index.php/cmr/ informes-de-gestion-del-cmr>. Acesso em: 01/2015.

CONSEJO Monetario Regional del Sistema Unitario de Compensación Regional de Pagos (SUCRE) (2013) “Informe de Gestión, 2012”. Disponível em: <http://www.sucrealba.org/index.php/cmr/ informes-de-gestion-del-cmr>. Acesso em: 01/2013. 
CONSEJO Monetario Regional del Sistema Unitario de Compensación Regional de Pagos (SUCRE) (2012) “Informe de Gestión, 2011”. Disponível em: <http://www.sucrealba.org/index.php/cmr/ informes-de-gestion-del-cmr>. Acesso em: 01/2013.

CONSEJO Monetario Regional del Sistema Unitario de Compensación Regional de Pagos (SUCRE) (2011) “Informe de Gestión, 2010”. Disponível em: <http://www.sucrealba.org/index.php/cmr/ informes-de-gestion-del-cmr>. Acesso em: 01/2013.

CONSEJO Monetario Regional del Sistema Unitario de Compensación Regional de Pagos (SUCRE) (2010). Sistema Unitario de Compensación Regional de Pagos. Disponível em: <http://www.bce. fin.ec/documentos/PublicacionesNotas/ComunicacionMedios/Documentos/R2DOC05.pdf>. Acesso em: 01/2013.

CHANG, Roberto (2000). "Regional monetary arrangements for developing countries”. Disponível em: <http://www.g24.org/Workshops/chang.pdf>. Acesso: 12/2012.

FRITZ, Barbara et al (2010). "Regional monetary arrangements for developing countries: a comparative analysis of regional payments systems”. FMM Conference, October, 29. Disponível em:<http://www.lai.fu-berlin.de/homepages/fritz/publikationen/Vortraege/Regional_Payment_ Systems_fmm291010.pdf>. Acesso em: 01/2013.

MUNEVAR, Daniel (2010). "El Sucre como alternativa a la crisis internacional”. Observatorio Internacional de la Deuda. Disponível em: <http://www.oid-ido.org/imprimer.php3?id_article=1159>. Acesso em: 11/2012.

PUÑAl., Antonio Martínez (2009). “O Acordo Marco da ALBA para o Sistema Único de Compensación Rexional de Pagos (SUCRE): algunhas consideracións.” Tempo Exterior n 19, vol. x (I).

RÍOS, Vladimir López (2010). "Sistemas de pago y complementación regional: Estrategias para Latinoamérica frente a la crisis económica mundial." Serie Documentos de Trabajo. n 115 . Banco Central de Venezuela.

ROSALES, Antulio (2010). El Banco del Sur y el sucre: (des)Acuerdos sobre una Arquitectura Financiera Alternativa”, Trabajo presentado en las Jornadas de Economía Crítica, Zaragoza, España, febrero. Disponível em: <http: http://www.ucm.es/info/ec/jec12/archivos/A4ECONOMIA\%20 MUNDIAL\%20Y\%20DESARROLLO/ORAL/ROSALES/ROSALES.pdf>. Acesso em: 01/2013.

SEVERO, Luciano Wexell (2010). El Sucre: Un instrumento para la integración. Disponível em: <http:// www.adital.com.br/site/noticia.asp?lang=ES\&cod=45266>. Acesso em: 01/2013

TRUJILLO, Freddy (2012). Sistema Unitário de Compensación de pagos (sucre) UNCTAD. Multi-Year Expert Meeting on International Cooperation: South-South Cooperation and Regional Integration. Fourth session

UNCTAD (2011). "Regional Monetary Cooperation and Growth-Enhancing Policies: The New Challenges for Latin America and the Caribbean". Study prepared by the secretariat of the United Nations Conference on Trade and Development. UNITED NATIONS, New York and Geneva. 